\title{
The Determinants of Relative Price Variability: Further EVIDENCE From Argentina*
}

\author{
María Angeles Caraballo \\ Universidad de Sevilla, España \\ CARLOS DABÚs \\ CONICET and Universidad Nacional del Sur, Argentina
}

This paper analyses the relative price variability (here after, RPVI) for Argentina from 1960 to 1993. We have distinguished a first period (1960-1975) with a moderate and stable inflation and a second one (1975-1993) with four inflation regimes: moderate, high, very high and hyperinflation. Results show that for the high, very high, and hyperinflation regimes, volatility and all components of inflation are relevant in explaining RPVI; but for the moderate regime, volatility and uncertainty are insignificant, and the impact of expected and unexpected inflation shocks depends on whether inflation is stable or not.

\section{JEL: E31}

Keywords: Relative Price Variability, Inflation Regimes, Markov Switching Model, Inflation Components.

\section{INTRODUCTION}

Macroeconomic theory emphasizes the distorting impact of inflation on relative price variability (RPVI). In fact, a relevant function of the price system is the transmission of the information required by economic agents in order to allocate resources efficiently. Given that such information is contained in relative prices, the noise coming from inflation can make it difficult to use the information optimally.

\footnotetext{
* We thank the financial support from Secretariado de Ciencia y Tecnología, Universidad Nacional del Sur (Argentina). Project PGI 24/E042. The assistance of Diego Caramuta is acknowledged. E-mail: mcaraba@us.es
} 
The positive relationship between RPV and inflation has practically become a stylized fact in economics ${ }^{1}$. However, there is no consensus regarding what component of inflation explains RPV: expected and unexpected inflation, ex ante inflation uncertainty and volatility have been proposed as determinants of RPV. Nonetheless, empirical evidence does not support unambiguously a particular approach. Our hypothesis is that this is due to the fact that the inflation-RPV relationship is very sensitive to inflation regimes. In particular, our goal is to show that the determinants of RPV change across different inflation regimes, and moreover, that for the same regime the results could differ for different inflationary contexts. In order to test our hypothesis, we analyze the Argentinian economy between 1960 and 1993, which is characterized by a very rich inflationary history. We distinguish a first period, from 1960 to 1975, where inflation was stable and low, and a second period (1975-1993) with a high and volatile inflation, where the monthly inflation rate oscillated from deflation to hyperinflation in 1989 and 1990.

The rest of the paper is organized as follows. Section 2 summarizes the theories linking inflation and RPV and main empirical evidence, section 3 presents the data and variables. In section 4 , we show the preliminary empirical evidence for the whole period under study, section 5 divides the period into inflation regimes using a Markov switching model and show the main determinants of RPV in each regime. Section 6 is focused on moderate inflation periods, and section 7 concludes.

\section{Main Theories AND EMPIRICAL Evidence}

Since the seminal papers of Vining and Elwertowski (1976) and Parks (1978), there is a vast literature showing a positive and strong relationship between inflation and RPV. The mechanisms underlying such correlation differ depending on the model used to explain it. The main theoretical approaches can be summarized as follows:

1. Signal-extraction model -Lucas (1972,1973), Barro (1976)- emphasizes the positive effect of ex ante inflation uncertainty on RPV. In this model ex ante inflation uncertainty generates "misperceptions" of absolute and relative prices, creating confusion between aggregate and relative shocks. However, realized aggregate shocks have no effect on RPV because all firms have identical price elasticity of supply; in other words, unexpected

\footnotetext{
${ }^{1}$ See, among others, Vining and Elwertowski (1976) for US, Parks (1978) for the Netherlands and US, Fischer (1981) for US, Fischer (1982) for Germany, Blejer and Leiderman (1982) and Palerm (1991) for Mexico, Quddus et al. (1988) and Tang and Wang (1993) for the Chinese hyperinflation, Van Hoomisen (1988) for Israel, Tommasi (1993) and Dabús (2000) for Argentina, Fielding and Mizen (2000) for ten countries of European Union, Silver and Ioannidis (2001) for nine European countries and Caraballo et al. (2006) for three Latin-American high inflation countries.
} 
inflation has no effect on RPV because all firms respond identically to any given aggregate shock.

2. The extension of the signal extraction model developed by Hercowitz (1981) and Cukierman (1983) points out the relevance of unexpected inflation in explaining RPV, given that firms are characterized by different price elasticity of supply and, hence, the responses of prices to unexpected aggregate demand shock are different. The key factor is the size of the shock and, therefore, the sign of unexpected inflation is irrelevant. Expected inflation plays no role in explaining RPV under neither of the versions of signal extraction model.

3. Menu costs model emphasizes the positive correlation between expected inflation and RPV. Within this model, the optimal policy is an $(S, s)$ price rule: the firm changes its nominal price when the real price hits a lower threshold, $s$, and the nominal price is changed so that the new real price equals a higher return point $S$. The distance between $S$ and $s$ increases with the expected value of inflation and, therefore, expected inflation affects RPV. Strictly speaking, these models compare the behavior of the price of a single product with the average inflation of that product, i.e. they have direct implications for intramarket RPV. But the common practice is to interpret the positive relation between expected inflation and intermarket RPV as an implication of the menu costs model.

4. Costly consumer search model tries to explain why the same good has different prices in the market, so the relevant variable is the intramarket RPV. In this model, the information's obsolescence due to inflation reduces the optimal stock of price information that consumers wish to hold, and as the consumers are differentially informed, inflation leads to a higher intramarket RPV. In general, as for menu costs model, a positive relationship between inflation and intermarket RPV is also interpreted as an evidence in favor of costly consumer search model.

Table 1 summarizes the empirical evidence according to each model. In short, empirical evidence is mixed and there is no consensus about the mechanisms linking inflation and RPV. Although recent works like Dabús (2000) for Argentina, Caglayan and Filiztekin (2003) for Turkey and Caraballo et al. (2006) ${ }^{2}$ for high

\footnotetext{
2 This paper presents relevant contributions respect to Caraballo et al. (2006). The main ones can be summarized as follows. Firstly, we include uncertainty as an additional determinant in explaining $R P V$ and we distinguish between positive and negative unexpected inflation, in order to take into account the predictions of the extended signal extraction model, which was omitted in Caraballo et al. (2006). Secondly, we focus not only on inflation regimes, as it is common in this literature, but on inflation context, which seems to play a key role in the RPV-inflation relationship. In third place, we pay special attention to moderate inflation regime. Finally, we introduce important changes in methodology. The most important ones are the use of a Markov switching model in order to classify regimes instead of imposing an exogenous criterion (Caraballo et al.; 2006) and also we check if results are sensitive to changes in the forecast equation of inflation and, finally, we tackle the presence of autocorrelation in a different way.
} 
inflation countries and Nautz and Scharff (2006) for the Euro area points out the relevance of inflation regimes in order to explain the determinants of RPV, there is a lack of literature about the role of inflation regimes in the "inflation-RPV" relationship itself, which this paper tries to fill.

TABLE 1

EMPIRICAL EVIDENCE ABOUT THE DETERMINANTS OF RPVI

\begin{tabular}{|c|c|c|c|}
\hline Model & $\begin{array}{l}\text { Prediction on } \\
\text { Inflation-RPV relation }\end{array}$ & $\begin{array}{l}\text { Empirical evidence } \\
\text { for each model }\end{array}$ & Mixed empirical evidence \\
\hline $\begin{array}{l}\text { 1. Signal } \\
\text { extraction }\end{array}$ & $\begin{array}{l}\text { + relation inflation } \\
\text { uncertainty/ } \\
\text { intermarket RPV }\end{array}$ & $\begin{array}{l}\text { Grier and Perry(1996; US) } \\
\text { Aarstol (1999; US) }\end{array}$ & $\begin{array}{l}\text { Binette and Martel } \\
\text { (2005; Canada): } \\
\text { inflation uncertainty is } \\
\text { significant only when } \\
\text { core inflation is used. }\end{array}$ \\
\hline $\begin{array}{l}\text { 2. Extension } \\
\text { of signal } \\
\text { extraction }\end{array}$ & $\begin{array}{l}\text { + relation unexpected } \\
\text { inflation / intermar- } \\
\text { ket RPV }\end{array}$ & $\begin{array}{l}\text { Parks (1978; USA) } \\
\text { Blejer (1981; Argentina) } \\
\text { Miszler and Nautz (2004; } \\
\text { Germany) } \\
\text { Nautz and Scharff (2005; } \\
\text { Germany) }\end{array}$ & $\begin{array}{l}\text { Fischer (1981, 1982; } \\
\text { US), Aarstol (1999; } \\
\text { US): RPV increases } \\
\text { with both expected } \\
\text { inflation and positive } \\
\text { unexpected inflation, } \\
\text { but not with negative } \\
\text { unexpected inflation. }\end{array}$ \\
\hline $\begin{array}{l}\text { 3. Menu } \\
\text { costs }\end{array}$ & $\begin{array}{l}\text { + relation expected } \\
\text { inflation/ intramarket } \\
\text { and intermarket RPV }\end{array}$ & $\begin{array}{l}\text { Lach and Tsiddon (1992; } \\
\text { Israel) } \\
\text { Binette and Martel (2005; } \\
\text { Canada) }\end{array}$ & $\begin{array}{l}\text { Tang and Wang } \\
\text { (1993; Chinese } \\
\text { hyperinflation): RPV } \\
\text { increases with both } \\
\text { expected inflation and } \\
\text { the absolute value of } \\
\text { unexpected inflation. } \\
\text { Silver and Ioannidis } \\
\text { (2001; nine European } \\
\text { countries): Negative } \\
\text { unexpected inflation/ } \\
\text { RPV relationship. }\end{array}$ \\
\hline $\begin{array}{l}\text { 4. Costly } \\
\text { consumer } \\
\text { search }\end{array}$ & $\begin{array}{l}\text { + relation inflation / } \\
\text { intramarket RPV }\end{array}$ & $\begin{array}{l}\text { Domberger (1987; UK), } \\
\text { Amano and Macklem (1997; } \\
\text { Canada) } \\
\text { Parsley (1996; some cities } \\
\text { in US) } \\
\text { Very high inflation: concave } \\
\text { relation RPV / Inflation } \\
\text { Danziger (1987; Israel) } \\
\text { Van Hoomisen (1988; Israel) } \\
\text { Tommasi (1993; Argentina) }\end{array}$ & \\
\hline
\end{tabular}




\section{DATA AND VARIABLES}

\subsection{Price data}

Price data series have been extracted from the statistical bulletins of the Instituto Nacional de Estadísticas y Censos (INDEC), from January, 1960 to November, 1993. Individual price data correspond to the items of the national Wholesale Price Index (WPI), at the level of WPI groups (i.e. three digits of the International Standard Industrial Classification). Since the structure of WPI in Argentina changed in July, 1984, we use 87 price indexes for the January, 1960-June, 1984 and 64 for the July, 1984-November, 1993 periods. Hence, over 36.000 price data are involved in our study.

\subsection{Variables}

As it is common in this kind of literature, the RPVI index (RPVI) is measured as the standard deviation of the individual price changes around the average inflation rate. We introduce a slight variation because at high inflation the usual RPVI can be spuriously correlated with the mean of the distribution -the average inflation rate-. In order to avoid this problem, we define RPVI as a coefficient of variation, as follows:

$$
R P V I_{t}=\frac{\sum_{i} w_{i t}\left(I N_{i t}-I N_{t}\right)^{2}}{\left(1+I N_{t}\right)^{2}}
$$

where $w_{i t}$ is the weight of price $i$ in the price index, $I N_{i t}$ is the inflation rate of price $i$ at month $t$ and $I N_{t}$ is the inflation rate at period $t$.

Inflation has been decomposed into expected, unexpected inflation and uncertainty $^{3}$, using the standard Box-Jenkins methodology ${ }^{4}$, and the model selected has been an ARMA $(1,1)-G A R C H(1,1)$ model. On one hand, the

\footnotetext{
${ }^{3}$ Obviously, there are different models for forecasting inflation, which could lead to different results. Altavilla and Ciccarelli (2007), analyzing the estimated effects of alternative monetary rules on unemployment dynamics in the Euro area and the US, show that there is no single model whose performance is clearly preferred; rather, a combination of forecasts appears most desirable. They analyze eight competing models: a drift-less random walk process; a univariate autoregressive moving-average model; a spectral model; a four-variable vector autoregressive model; an exponential smooth transition autoregressive model, a univariate Markov-switching autoregressive model; a Markov-switching VAR; and a combination of all the previous methods. Finally, we have chosen a univariate autoregressive moving-average model for forecasting inflation and a univariate Markov-switching autoregressive model to obtain inflation regimes.

${ }^{4}$ As it is well known, the first step to model uncertainty with the variance of the errors terms of the inflation model is to test if inflation is stationary, if this is not the case, the variance of errors explodes and it makes no sense to use such variance as a proxy of uncertainty. The results of test for stationary are shown in Appendix I.
} 
expected inflation $(E I N)$ is that rate forecast by economic agents for the current period and unexpected inflation $(U I N)$ is the error of expected inflation, which results from the difference between the actual and the expected inflation $(U I N=I N-E I N)$. On the other hand, an inflation model signals uncertainty when the forecast errors are heteroskedastic. The specification of a GARCH (Generalized Autoregressive Conditional Heteroskedasticity) equation for the error term variance of the inflation model allows us to estimate a proxy for inflation uncertainty. By the simultaneous estimate of the inflation model and the GARCH equation, the following new inflation model is obtained in which the forecast errors are homocedastic:

$$
\begin{aligned}
& I N_{t}=a_{0}+a_{1} I N_{t-1}+a_{2} \varepsilon_{t-1}+\varepsilon_{t} \\
& \sigma_{\varepsilon t}^{2}=b_{0}+b_{1} \varepsilon_{t-1}^{2}+b_{2} \sigma_{\varepsilon, t-1}^{2}
\end{aligned}
$$

where $\sigma_{\varepsilon t}^{2}$ is the inflation uncertainty.

Equations (2) and (3) were estimated using the Marquardt algorithm. As the residuals were not conditionally normally distributed, we compute the covariance matrix and standard errors using the methods proposed by Bollerslev and Wooldridge (1992). The $p$-value of the $z$-statistic is shown into brackets.

$$
\begin{aligned}
& I N_{t}=\underset{(0.11)}{0.12}+\underset{(0.00)}{0.96} I N_{t-1}-\underset{(0.00)}{0.42} \varepsilon_{t-1}+\varepsilon_{t} \\
& \sigma_{\varepsilon t}^{2}=\underset{(0.20)}{0.35}+\underset{(0.00)}{0.89} \varepsilon_{t-1}^{2}+\underset{(0.00)}{0.53} \sigma_{\varepsilon, t-1}^{2}
\end{aligned}
$$

Adjusted $\mathrm{R}^{2}=0.33$

Equation (3') is used to construct the series of uncertainty.

Finally, we have distinguished volatility from uncertainty. Volatility is an ex post concept that is commonly measured by the standard deviation of monthly inflation around the annual inflation rate. Meanwhile, uncertainty is an ex ante and subjective concept, which depends intrinsically on the mechanism of inflation forecasting chosen by agents. Thus, less information about the future can provoke high uncertainty, even though in cases of low volatility of ex post information. On the contrary, with enough information on future events (for example on changes in economic policy measures), agents will have less uncertainty, compatible with high macroeconomic volatility. The inclusion of this variable does not obey to a precise economic model but to the fact that we are working with a country strongly characterized by instability, and volatility tries to capture the relevance of such instability. In fact, the difference between uncertainty and volatility, and the importance given to volatility, is found in recent literature only for countries with high inflation -see, for example, Dabús (2000) for Argentina, Fernández (2000) for Paraguay and Solera (2002) for Costa Rica. 
As we are using monthly data, we define volatility as the absolute value of the difference between the current inflation rate and a moving average inflation rate of three, six and 12 months, respectively:

$$
V O L_{t}=\left|I N_{t}-\frac{1}{2 i+1} \sum_{j=-i}^{i} I N_{t+j}\right| \quad i=3,6,12
$$

The selection of the number of lags is arbitrary. Nevertheless, the idea of including a number of lags that span from 3 to 12 months is to capture the influence of the inflationary environment on the current inflation rate in an economy of high and volatile inflation like Argentina. Intuitively, above 12 months, the values of volatility could be affected by far away high fluctuations that in fact would not be related to the period of time for which volatility is calculated, and therefore an overestimation error could arise. On the contrary, a number of lags under three can generate an underestimation of the volatility, because movements of inflation trend, relatively closed to the current inflation, should be excluded from the measure.

\section{Preliminary Empirical Results}

This section presents the empirical results of the Inflation-RPVI relationship for the period under study. The estimates were carried out following the main theoretical models developed in the literature -see Section 2-. Firstly, we estimate the effects of the inflation rate on RPVI; secondly, we consider the role of expected and unexpected inflation, and finally we analyze the impact of uncertainty and volatility on RPVI.

In first place, we regress RPVI on squared inflation -equation (5)- to capture non-linearities in such relation, and the absolute of inflation -equation (6) - to determine the effect of the magnitude of inflation on RPVI, independently of its sign. The lagged term of RPVI is included to capture the persistence of the variable. The estimated equations are:

$$
\begin{aligned}
& R P V I_{t}=\alpha+\beta I N_{t}^{2}+\lambda R P V I_{t-1}+\varepsilon_{t} \\
& R P V I_{t}=\alpha+\beta\left|I N_{t}\right|+\lambda R P V I_{t-1}+\varepsilon_{t}
\end{aligned}
$$

Our start point is to test if $\beta>0$ for both equations result that is in accordance with the four theories mentioned above and it is the first step in order to further analysis of the determinants of RPVI. Results are presented in Table 2, where we have also included the estimates with the lagged terms of inflation to reduce the problems associated with the simultaneous determination of both variables, as pointed out by Grier and Perry (1996). 
TABLE 2

INFLATION-RPVI RELATION: JANUARY 1960-NOVEMBER 1993

Dependent variable: RPVI

\begin{tabular}{lcccccccc}
\hline Estimates & $\alpha$ & $\mathrm{RPVI}_{\mathrm{t}-1}$ & $\mathrm{IN}_{\mathrm{t}}^{2}$ & $\mathrm{IN}_{\mathrm{t}-1}^{2}$ & $\left|\mathrm{IN}_{\mathrm{t}}\right|$ & $\left|\mathrm{IN}_{\mathrm{t}-1}\right|$ & Adj. $\mathrm{R}^{2}$ & $\mathrm{BG}$ \\
\hline $\mathrm{I}$ & 0.36 & 0.43 & & & & & 0.18 & 0.45 \\
& $(0.00)$ & $(0.00)$ & & & & & & \\
$\mathrm{II}^{+}$ & 0.43 & 0.06 & 0.0005 & & & & 0.80 & 0.95 \\
& $(0.00)$ & $(0.04)$ & $(0.00)$ & & & & & \\
$\mathrm{III}$ & 0.44 & 0.24 & & 0.0001 & & & 0.20 & 0.25 \\
& $(0.02)$ & $(0.52)$ & $(0.51)$ & & & & \\
$\mathrm{IV}^{+}$ & -0.03 & 0.007 & & & 0.08 & & 0.68 & 0.72 \\
& $(0.79)$ & $(0.91)$ & & & $(0.00)$ & & & \\
$\mathrm{V}$ & 0.21 & -0.03 & & & & 0.05 & 0.33 & 0.46 \\
& $(0.00)$ & $(0.93)$ & & & & $(0.08)$ & & \\
\hline
\end{tabular}

Notes: For all tables $t$-statistics are based on standard errors computed according to Newey-West procedure to allow for residuals that exhibit both autocorrelation and heteroskedasticity of unknown form. The terms in brackets are the p-values associated to t-statistics. BG is the p-value of the $\chi^{2}$ statistics when the null hypothesis of the test is that there is no serial correlation in the residuals up to the first order.

+ These estimates include a MA(5) structure in the residuals.

Along the paper, to test for autocorrelation we use the Breusch-Godfrey (BG) Lagrange multiplier test. Firstly, we estimate equations by Ordinary Least Squares (OLS), after that, we test for first and up to twelfth order autocorrelation in residuals. If no autocorrelation appears, we present the results of the OLS estimate. When autocorrelation is detected, we estimate by Non Linear Least Squares and, previously, we model the structure of the residuals attending to the autocorrelation properties shown by the residuals series. For all cases, residuals have been modeled using a moving average structure, its order depends on each case.

Table 2 shows a positive and significant effect of current inflation on RPVI in both specifications: with squared and absolute values of inflation. Lagged absolute value of inflation is significant at $10 \%$ and lagged squared inflation is not significant. Hence, the main effect of inflation on relative prices is due to the contemporaneous relation between them, with decreasing impacts of past inflation.

In second place, we estimate the effects of inflation expectations on RPVI -equations (7) and (8)- and we test if the asymmetric response of RPVI to positive and negative unexpected inflation is significant.

$$
\begin{aligned}
& R P V I_{t}=\alpha+\beta_{0} \operatorname{EIN}_{t}+\beta_{1} \operatorname{UIN}_{t}+\lambda R P V I_{t-1}+\varepsilon_{t} \\
& R P V I_{t}=\alpha+\beta_{0} \operatorname{EIN}_{t}+\beta_{2} \operatorname{UIN}_{t}^{+}+\beta_{3} \operatorname{UIN}_{t}^{-}+\lambda R P V I_{t-1}+\varepsilon_{t}
\end{aligned}
$$


where $U I N^{+}$and $U I N^{-}$denote the positive and negative unexpected inflation, respectively. Recall that, on one hand, menu costs model predicts $\beta_{0}>0$ and, on the other hand, $\beta_{2}=\beta_{3}>0$ can be considered as evidence in favor of the extended signal extraction model.

Results are presented in Table 3. Both expected and unexpected inflation affect positively RPVI and Wald test shows that there are not asymmetric effects of unexpected inflation ${ }^{5}$. Thus, the magnitude (but not the sign) of the inflationary surprise is relevant to explain RPVI.

TABLE 3

RPVI AND INFLATION EXPECTATIONS. ARGENTINA JANUARY 1960-NOVEMBER 1993

Dependent variable: RPVI

\begin{tabular}{lcccccccc}
\hline Estimates & $\alpha$ & $\mathrm{RPVI}_{\mathrm{t}-1}$ & $\mathrm{EIN}_{\mathrm{t}}$ & $\mathrm{UIN}_{\mathrm{t}}$ & $\mathrm{UIN}_{\mathrm{t}}^{+}$ & $\mathrm{UIN}_{\mathrm{t}}^{-}$ & Adj. $^{2}$ & $\mathrm{BG}$ \\
\hline I & 0.01 & 0.39 & 0.04 & 0.08 & & & 0.66 & 0.19 \\
& $(0.84)$ & $(0.00)$ & $(0.00)$ & $(0.00)$ & & & & \\
$\mathrm{II}$ & 0.02 & 0.38 & 0.04 & & 0.08 & 0.07 & 0.66 & 0.17 \\
& $(0.76)$ & $(0.00)$ & $(0.02)$ & $(0.00)$ & $(0.00)$ & & \\
& \multicolumn{7}{c}{ Wald test: $\mathrm{H}_{\mathrm{o}}: \beta_{2}=\beta_{3}$} \\
& $\chi^{2}(1)$ statistics: 0.18 \\
\end{tabular}

In order to analyze the role of uncertainty, we have considered firstly the models existing in the literature, focusing on Grier and Perry (1996). These authors propose a bivariate GARCH-M model of inflation and RPV to show that inflation uncertainty dominates trend inflation as predictor of RPV. We try to apply the same specification for RPVI in Argentina and, therefore, we have to test if the conditional variance of RPVI is constant. As first step, we have to model RPVI. The best fit is an ARMAX $(1,5)$ with $I N_{t}^{2}$ as explanatory variable (see estimate II in Table 2). We test the hypothesis of independence of the squared of the residuals $^{6}$ : the Ljung-Box Q-Statistics adjusted for five ARMA terms is 116.31 and the Autoregressive Conditional Heteroskedasticity Lagrange Multiplier (ARCH-LM) statistics, which is asymptotically distributed as $\chi^{2}(1)$, is 52.25 . Therefore, the two statistics lead us to reject the null at the $1 \%$, which implies that the conditional variance of RPVI is not constant. Secondly, we have considered alternatives ways to model RPVI and we have chosen estimates IV and V in Table 2, where the absolute inflation and its lagged value appears to be significant at $1 \%$ and $10 \%$ respectively. For estimate IV, the Ljung-Box Q-Statistics adjusted for five

\footnotetext{
${ }^{5}$ For Wald test, the $\chi^{2}$ statistic is reported given that the variances have been estimated using the NeweyWest method, and therefore the F-statistics does not possess the desired finite-sample properties.

${ }^{6} \mathrm{We}$ omit results of test of autocorrelation because they appear in Table 2 .
} 
ARMA terms is 44.36 and the ARCH-LM test statistics is 5.65; for estimate V, the Q-statistics is 67.72 and the ARCH-LM test statistics is 65.09. Therefore, for both cases we reject again the hypothesis of independence of the squared of the residuals at the $1 \%$, so, as the conditional variance of RPVI is not constant, we have not applied the proposal of Grier and Perry. Instead, and in order to have a first overview of the role of uncertainty, we redefine the above $\operatorname{ARMAX}(1,5)$ model including uncertainty as explanatory variable too, and given the structure of the residuals, we estimate equations (9) and (10):

$$
\begin{aligned}
& R P V I_{t}=\alpha+\beta I N_{t}^{2}+\lambda R P V I_{t-1}+\rho U N_{t}+\sum_{i=1}^{5} \delta_{i} \varepsilon_{t-i}+\varepsilon_{t} \\
& \sigma_{\varepsilon t}=\phi_{1}+\phi_{2} \varepsilon_{t-1}^{2}
\end{aligned}
$$

We use the Marquardt algorithm and the covariance matrix and standard errors are computed using Bollerslev and Wooldridge's method. The $p$-value of the $z$-statistic is shown into brackets.

$$
\begin{array}{lll}
\text { (9') } & R P V I_{t}=\underset{0.00}{0.26}+\underset{0.00}{0.0006} I N_{t}^{2}+\underset{0.01}{0.14} R P V I_{t-1}+\underset{0.63}{0.00006 U N_{t}+v_{t}} \\
& \\
\text { (10') } \sigma_{\varepsilon t}=\underset{0.00}{0.02+\underset{0.00}{2.40} \varepsilon_{t-1}^{2}} & \text { Adjusted } \mathrm{R}^{2}=0.58
\end{array}
$$

where $^{7} \quad v_{t}=\sum_{i=1}^{5} \delta_{i} \varepsilon_{t-i}+\varepsilon_{t}$

Analogously, we have used the same method for volatility, so we have estimated again equations (9) and (10) but including volatility instead of uncertainty, the three measures of volatility appear to be significant-see Appendix A for results-.

In short, this preliminary analysis show that inflation rate, both the absolute and squared values, expected and unexpected inflation and volatility play a key role in explaining RPVI, while uncertainty has the expected sign but it is not significant, in contrast to results found by Grier and Perry (1996) and Aarstol (1999). Moreover, the relevance of squared inflation indicates a non-linear relation between inflation and RPVI. The intuition behind this result is such relation, and then the determinants of RPVI, changes across inflation regimes. This hypothesis is analyzed in next sections.

\footnotetext{
${ }^{7}$ Estimates of $v_{\mathrm{t}}$ are not included because they are not relevant for the goals of this paper.
} 


\section{The Role Of Inflation Regimes}

We determine the inflation regimes in Argentina applying the methodology based on Markov switching regression model -see Hamilton $(1989,1994)$ - Within this method, regimes are defined using a model that endogenously shows the probability of being in a regime. We assume that a particular period can be included in a specific regime when the probability of being in such regime is above 0.5 ; and specify the Markov switching regression model as an autoregressive model of order one with three states of inflation -see Appendix B for details-. To estimate this model we used a reformulated version of the Hamilton's algorithm. Since the algorithm does not converge to any result for the whole series, the hyperinflation months were removed from the estimation. Hence, we obtained four regimes, one of hyperinflation, which includes the periods previously excluded from the sample, and three regimes (moderate, high and very high inflation) that were determined by the model.

Using the maximum likelihood estimates for the transition probabilities matrix, the whole sample is divided into four different regimes, as it can be seen in Table 4. Moreover, such Table shows that the whole sample could be divided into a first period of moderate and stable inflation from January 1960 to May 1975, followed by a long period of changing inflation where, along 222 months, inflation goes from negative rates to hyperinflation and within this latter period, the four mentioned regimes can be distinguished.

TABLE 4

INFLATION REGIMES

\begin{tabular}{|c|c|c|c|c|}
\hline Regime & $\begin{array}{c}\text { Number of } \\
\text { months }\end{array}$ & Max. & Min. & Months \\
\hline $\begin{array}{l}\text { Moderate } \\
\text { Inflation }\end{array}$ & 354 & $16.6 \%$ & $-1.9 \%$ & $\begin{array}{c}\text { 1960(1)-1975(5), 1975(8)-1975(12), } \\
\text { 1976(5)-1981(5), 1981(8)-1982(6), 1982(8), } \\
\text { 1982(10)-1983(1), 1983(3)1983(7), 1985(7)- } \\
\text { 1987(9), 1987(11)-1988(2), 1988(9)-1989(2), } \\
\text { 1989(8)-1989(11), 1990(4)-1990(7), } \\
\text { 1990(10)-1991(1), 1991(3)-1993(11) }\end{array}$ \\
\hline $\begin{array}{l}\text { High } \\
\text { Inflation }\end{array}$ & 41 & $32.1 \%$ & $9.1 \%$ & $\begin{array}{c}\text { 1975(7), 1976(1)-1976(2), 1976(4), } \\
\text { 1981(6)-1981(7), 1982(7),1982(9),1983(2), } \\
\text { 1983(8)-1985(5), 1987(10), } \\
1988(3)-1988(8), 1989(3), 1990(8)-1990(9)\end{array}$ \\
\hline $\begin{array}{l}\text { Very High } \\
\text { Inflation }\end{array}$ & 4 & $48.6 \%$ & $37.9 \%$ & 1975(6), 1985(6),1989(12), 1991(2) \\
\hline $\begin{array}{l}\text { Hyper- } \\
\text { inflation }\end{array}$ & 8 & $209.1 \%$ & $54.1 \%$ & 1976(3),1989(4)-1989(7),1990(1)- 1990(3) \\
\hline
\end{tabular}

Once the inflation regimes were obtained, we include them in the estimates by means of the corresponding dummies to each regime and we carry out the basic regressions that appear in Table 5. 
TABLE 5

RPVI AND INFLATION REGIMES.1960-1993.

Dependent Variable: RPVI

\begin{tabular}{|c|c|c|c|c|c|c|c|c|}
\hline Estimates & $\begin{array}{c}\mathrm{I}^{(+)} \\
\mathrm{IN}_{\mathrm{t}} \mathrm{l}\end{array}$ & $\begin{array}{l}\mathrm{II}^{(+)} \\
\mathrm{IN}_{\mathrm{t}}^{2}\end{array}$ & $\begin{array}{c}\mathrm{III} \\
\text { EIN }_{\mathrm{t}}\end{array}$ & $\begin{array}{c}\text { IV } \\
\text { UIN }_{t}\end{array}$ & $\begin{array}{l}\mathrm{V}^{(+)} \\
\mathrm{UN}_{\mathrm{t}}\end{array}$ & $\begin{array}{c}\mathrm{VI}^{(+)} \\
\mathrm{VOL}_{\mathrm{t}, 3}\end{array}$ & $\begin{array}{l}\mathrm{VII}^{(+)} \\
\mathrm{VOL}_{\mathrm{t}, 6}\end{array}$ & $\begin{array}{l}\mathrm{VIII}^{(+)} \\
\mathrm{VOL}_{\mathrm{t}, 12}\end{array}$ \\
\hline Moderate & $\begin{array}{c}0.08 \\
(0.00)\end{array}$ & $\begin{array}{l}0.003 \\
(0.00)\end{array}$ & $\begin{array}{l}-0.02 \\
(0.14)\end{array}$ & $\begin{array}{l}0.04 \\
(0.00)\end{array}$ & $\begin{array}{c}-0.00001 \\
(0.84)\end{array}$ & $\begin{array}{l}0.009 \\
(0.51)\end{array}$ & $\begin{array}{c}-0.008 \\
(0.65)\end{array}$ & $\begin{array}{c}-0.008 \\
(0.59)\end{array}$ \\
\hline High & $\begin{array}{c}0.05 \\
(0.00)\end{array}$ & $\begin{array}{l}0.001 \\
(0.05)\end{array}$ & $\begin{array}{c}0.19 \\
(0.02)\end{array}$ & $\begin{array}{c}0.02 \\
(0.04)\end{array}$ & $\begin{array}{l}0.002 \\
(0.06)\end{array}$ & $\begin{array}{c}0.05 \\
(0.04)\end{array}$ & $\begin{array}{c}0.04 \\
(0.07)\end{array}$ & $\begin{array}{c}0.05 \\
(0.06)\end{array}$ \\
\hline Very High ${ }^{(*)}$ & $\begin{array}{c}0.05 \\
(0.02)\end{array}$ & $\begin{array}{l}0.001 \\
(0.04)\end{array}$ & $\begin{array}{c}0.09 \\
(0.10)\end{array}$ & $\begin{array}{c}0.09 \\
(0.04)\end{array}$ & $\begin{array}{c}-0.00014 \\
(0.79)\end{array}$ & $\begin{array}{c}0.09 \\
(0.09)\end{array}$ & $\begin{array}{c}0.08 \\
(0.06)\end{array}$ & $\begin{array}{c}0.09 \\
(0.05)\end{array}$ \\
\hline Hyper. & $\begin{array}{c}0.09 \\
(0.00)\end{array}$ & $\begin{array}{c}0.0005 \\
(0.00)\end{array}$ & $\begin{array}{c}0.11 \\
(0.00)\end{array}$ & $\begin{array}{c}0.12 \\
(0.00)\end{array}$ & $\begin{array}{l}0.001 \\
(0.00)\end{array}$ & $\begin{array}{c}0.14 \\
(0.00)\end{array}$ & $\begin{array}{c}0.12 \\
(0.00)\end{array}$ & $\begin{array}{c}0.11 \\
(0.00)\end{array}$ \\
\hline $\mathrm{RPVI}_{\mathrm{t}-1}$ & $\begin{array}{l}-0.07 \\
(0.36)\end{array}$ & $\begin{array}{c}0.09 \\
(0.04)\end{array}$ & $\begin{array}{c}0.39 \\
(0.01)\end{array}$ & $\begin{array}{c}0.49 \\
(0.00)\end{array}$ & $\begin{array}{c}0.26 \\
(0.00)\end{array}$ & $\begin{array}{c}0.10 \\
(0.14)\end{array}$ & $\begin{array}{c}0.04 \\
(0.57)\end{array}$ & $\begin{array}{c}0.07 \\
(0.42)\end{array}$ \\
\hline$\alpha$ & $\begin{array}{c}0.10 \\
(0.25)\end{array}$ & $\begin{array}{c}0.30 \\
(0.00)\end{array}$ & $\begin{array}{c}0.35 \\
(0.00)\end{array}$ & $\begin{array}{l}0.24 \\
(0.00)\end{array}$ & $\begin{array}{c}0.33 \\
(0.00)\end{array}$ & $\begin{array}{c}0.44 \\
(0.00)\end{array}$ & $\begin{array}{c}0.42 \\
(0.00)\end{array}$ & $\begin{array}{c}0.40 \\
(0.00)\end{array}$ \\
\hline $\begin{array}{l}\text { Adj. } \mathrm{R}^{2} \\
\text { BG } \\
\chi^{{ }^{2}(3)}{ }^{(* *)}\end{array}$ & $\begin{array}{l}0.70 \\
0.66 \\
7.56\end{array}$ & $\begin{array}{r}0.81 \\
0.88 \\
12.15\end{array}$ & $\begin{array}{r}0.60 \\
0.57 \\
12.37\end{array}$ & $\begin{array}{r}0.65 \\
0.35 \\
12.73\end{array}$ & $\begin{array}{r}0.56 \\
0.71 \\
23.17\end{array}$ & $\begin{array}{r}0.75 \\
0.92 \\
27.72\end{array}$ & $\begin{array}{r}0.72 \\
0.06 \\
13.36\end{array}$ & $\begin{array}{r}0.74 \\
0.68 \\
18.48\end{array}$ \\
\hline
\end{tabular}

Notes: ${ }^{(+)}$Estimates I and II include a MA(5) structure in the residuals. Estimates V, VI, VII and VIII include a MA(6) structure in the residuals. (*) Results for very high inflation regime must be taken cautiously because such regime only includes four months. (**) $\chi^{2}(3)$ statistic when the null hypothesis is that the coefficients of the variables across the four inflation regimes are equal. BG: Breusch-Godfrey test.

Table 5 shows that results change when inflation regimes are included. On one hand, when we test if the coefficients are jointly equal, the $\chi^{2}(3)$ statistic leads us to reject the null. As far as significance of the variables is concerned, on one hand, squared inflation and unexpected inflation are significant at $5 \%$ or $1 \%$ in all regimes. On the other hand, expected inflation, uncertainty and volatility affect RPVI only beyond moderate inflation: they are significant at $5 \%$ or $10 \%$ for high and very high inflation (except uncertainty which is not significant in very high inflation) and at $1 \%$ for hyperinflation. In short, the results differ between moderate inflation and the other regimes. Thus, we carry out a deeper analysis of such regime. In order to do that, we have to take into account that we have two kind of moderate regime, the one in the first period of stable inflation, and the moderate inflation within a period of changing inflation. We consider both kinds of moderate inflation regimes separately.

\section{DETERMINANTS OF RPVI In MODERATE INFLATION}

This section analyses the determinants of RPVI in moderate inflation. Table 6 shows the results for the stable period, which spans from January 1960 to May 
1975, and Table 7 presents the results for moderate inflation regime occurred along the unstable inflation period that goes from June 1975 to November $1993^{8}$.

TABLE 6

RPVI IN MODERATE INFLATION REGIME. STABLE INFLATION PERIOD Dependent Variable: RPVI

\begin{tabular}{|c|c|c|c|c|c|c|c|c|}
\hline Estimates & $\begin{array}{c}\mathrm{I} \\
\mathrm{I} \mathrm{IN}_{\mathrm{t}} \mathrm{I} \\
\end{array}$ & $\begin{array}{c}\mathrm{II} \\
\mathrm{IN}_{\mathrm{t}}^{2} \\
\end{array}$ & $\begin{array}{c}\mathrm{III} \\
\text { EIN }_{\mathrm{t}}\end{array}$ & $\begin{array}{c}\text { IV } \\
\text { UIN }_{\mathrm{t}}\end{array}$ & $\begin{array}{c}\mathrm{V} \\
\mathrm{UN}_{\mathrm{t}}\end{array}$ & $\begin{array}{c}\mathrm{VI}^{(+)} \\
\mathrm{VOL}_{\mathrm{t}, 3} \\
\end{array}$ & $\begin{array}{c}\mathrm{VII}^{(+)} \\
\mathrm{VOL}_{\mathrm{t}, 6} \\
\end{array}$ & $\begin{array}{c}\mathrm{VIII} \\
\mathrm{VOL}_{\mathrm{t}, 12}\end{array}$ \\
\hline & $\begin{array}{c}0.06 \\
(0.00)\end{array}$ & $\begin{array}{l}0.005 \\
(0.00)\end{array}$ & $\begin{array}{c}0.04 \\
(0.00)\end{array}$ & $\begin{array}{c}0.02 \\
(0.08)\end{array}$ & $\begin{array}{l}0.003 \\
(0.20)\end{array}$ & $\begin{array}{c}0.01 \\
(0.43)\end{array}$ & $\begin{array}{c}0.01 \\
(0.35)\end{array}$ & $\begin{array}{c}0.01 \\
(0.22)\end{array}$ \\
\hline $\mathrm{RPVI}_{\mathrm{t}-1}$ & $\begin{array}{c}0.15 \\
(0.04)\end{array}$ & $\begin{array}{c}0.14 \\
(0.06)\end{array}$ & $\begin{array}{c}0.15 \\
(0.03)\end{array}$ & $\begin{array}{c}0.23 \\
(0.00)\end{array}$ & $\begin{array}{c}0.19 \\
(0.02)\end{array}$ & $\begin{array}{c}0.64 \\
(0.00)\end{array}$ & $\begin{array}{c}0.66 \\
(0.00)\end{array}$ & $\begin{array}{c}0.65 \\
(0.00)\end{array}$ \\
\hline$\alpha$ & $\begin{array}{c}0.16 \\
(0.00)\end{array}$ & $\begin{array}{c}0.26 \\
(0.00)\end{array}$ & $\begin{array}{c}0.21 \\
(0.00)\end{array}$ & $\begin{array}{c}0.29 \\
(0.00)\end{array}$ & $\begin{array}{c}0.27 \\
(0.00)\end{array}$ & $\begin{array}{c}0.13 \\
(0.03)\end{array}$ & $\begin{array}{c}0.12 \\
(0.06)\end{array}$ & $\begin{array}{c}0.13 \\
(0.05)\end{array}$ \\
\hline Adj. $R^{2}$ & 0.1 & 0.1 & 0.0 & 0.0 & 0.0 & 0.06 & 0.0 & 0.06 \\
\hline BG & 0.97 & 0.41 & 0.06 & 0.10 & 0.10 & 0.12 & 0.19 & 0.14 \\
\hline
\end{tabular}

Notes: (+) estimates including a MA(1) term in residuals. BG: Breusch-Godfrey test.

TABLE $7^{9}$

RPVI IN MODERATE INFLATION REGIME. CHANGING INFLATION PERIOD Dependent Variable: RPVI

\begin{tabular}{lcccccccc}
\hline \multirow{2}{*}{ Estimates } & $\mathrm{I}^{(+)}$ & $\mathrm{II}^{(+)}$ & $\mathrm{III}$ & $\mathrm{IV}$ & $\mathrm{V}^{(+)}$ & $\mathrm{VI}^{(+)}$ & $\mathrm{VII}^{(+)}$ & $\mathrm{VIII}^{(+)}$ \\
& $\mathrm{I} \mathrm{IN}_{\mathrm{t}} \mathrm{I}$ & $\mathrm{IN}_{\mathrm{t}}^{2}$ & $\mathrm{EIN}_{\mathrm{t}}$ & $\mathrm{UIN}_{\mathrm{t}}$ & $\mathrm{UN}_{\mathrm{t}}$ & $\mathrm{VOL}_{\mathrm{t}, 3}$ & $\mathrm{VOL}_{\mathrm{t}, 6}$ & $\mathrm{VOL}_{\mathrm{t}, 12}$ \\
\hline \multirow{3}{*}{ RPVI $_{\mathrm{t}-1}$} & 0.08 & 0.003 & -0.03 & 0.04 & -0.000002 & 0.01 & 0.01 & 0.01 \\
& $(0.00)$ & $(0.00)$ & $(0.10)$ & $(0.00)$ & $(0.99)$ & $(0.26)$ & $(0.12)$ & $(0.40)$ \\
$\alpha$ & -0.07 & 0.09 & 0.44 & 0.51 & 0.51 & -0.03 & -0.007 & 0.01 \\
& $(0.35)$ & $(0.05)$ & $(0.01)$ & $(0.00)$ & $(0.00)$ & $(0.38)$ & $(0.92)$ & $(0.86)$ \\
& -0.05 & 0.32 & 0.46 & 0.27 & 0.19 & 0.55 & 0.59 & 0.55 \\
& $(0.75)$ & $(0.00)$ & $(0.00)$ & $(0.00)$ & $(0.01)$ & $(0.00)$ & $(0.00)$ & $(0.00)$ \\
\hline Adj. $\mathrm{R}^{2}$ & 0.72 & 0.82 & 0.61 & 0.66 & 0.59 & 0.83 & 0.74 & 0.76 \\
BG & 0.16 & 0.23 & 0.99 & 0.96 & 0.93 & 0.85 & 0.51 & 0.71 \\
\hline
\end{tabular}

Notes: Estimates I and II include a MA(1) term in residuals; estimate V, a MA(5); estimate VI, MA(6) and estimates VII and VIII, a MA(1). BG: Breusch-Godfrey test.

\footnotetext{
${ }^{8}$ As Table 4 shows, moderate inflation in this period covers the following months: August 1975-December 1975, May 1976-May 1981, August 1981-June 1982, August 1982, October 1982-January 1983, March 1983-July 1983, July 1985-September 1987, November 1987-February 1988, September 1988-February 1989, August 1989-November 1989, April 1990-July 1990, October 1990-January 1991, March 1991-November 1993.

9 Table 7 does not include the results for the three others inflation regimes because they do not change with respect to Table 5 .
} 
As it can be seen from Tables 6 and 7, in both cases, the absolute inflation rate and the squared inflation are significant, and uncertainty and volatility are not significant. The main difference appears with expected and unexpected inflation, given that in a stable inflation period, expected inflation is significant and unexpected inflation is not significant at $5 \%$, and the reverse is true for the moderate inflation regime in the changing inflation period.

If we consider an asymmetric impact of unexpected inflation, results in Table 8 show that for stable period only positive unexpected inflation is significant, while in the changing inflation period the magnitude and not the sign is relevant. The $\chi^{2}(1)$ statistics implies that asymmetries appear in the stable period but not in the changing inflation period ${ }^{10}$.

TABLE 8

RPVI AND UNEXPECTED INFLATION IN MODERATE INFLATION REGIME Dependent Variable: RPVI

\begin{tabular}{lcc}
\hline & Stable inflation period & Changing inflation period \\
\hline $\mathrm{UIN}_{\mathrm{t}}^{+}$ & 0.09 & 0.02 \\
& $(0.00)$ & $(0.05)$ \\
$\mathrm{UIN}_{\mathrm{t}}^{-}$ & -0.04 & 0.04 \\
& $(0.14)$ & $(0.00)$ \\
$\mathrm{RPVI}_{\mathrm{t}-1}$ & 0.14 & 0.51 \\
& $(0.14)$ & $(0.00)$ \\
$\alpha$ & 0.21 & 0.29 \\
& $(0.00)$ & $(0.00)$ \\
\hline Adj. $\mathrm{R}^{2}$ & & 0.65 \\
$\mathrm{BG}$ & 0.10 & 0.99 \\
$\chi^{2}(1)$ & 0.35 & 0.49 \\
\hline
\end{tabular}

Notes: $\chi^{2}$ statistic when the null hypothesis is that the coefficients of positive and negative unexpected inflation are equal. BG: Breusch-Godfrey test.

Finally, we check if the results are sensitive to changes in the forecast equation of inflation. When we consider the two periods separately, for the second period the best model to fit inflation is the ARMA $(1,1)-\mathrm{GARCH}(1,1)$ selected for the whole sample, but this does not hold for the stable period. Applying again the standard Box-Jenkin methodology, the best fit for inflation in the stable period is:

\footnotetext{
${ }^{10}$ It makes no sense to analyse the asymmetric effects of unexpected inflation for high, very high and hyperinflation regimes, because for all of them, except for few months in the high inflation period, unexpected inflation is always positive.
} 


$$
\begin{aligned}
& I N_{t}=\underset{(0.00)}{0.61}+\underset{(0.00)}{0.49} I N_{t-1}+\underset{(0.00)}{0.15 I N_{t-3}}+\varepsilon_{t} \\
& \sigma_{\varepsilon t}^{2}=\underset{(0.00)}{1.89+\underset{(0.01)}{0.53} \varepsilon_{t-1}^{2}}
\end{aligned}
$$

As usual along the paper, we have applied the Marquardt algorithm and the $p$-value of the $z$-statistic computed using Bollerslev and Wooldridge's method is shown into brackets. From the above model, we obtain expected and unexpected inflation and we estimate equation (8) by means of OLS, given that residuals do not present autocorrelation:

$$
R P V I_{t}=\underset{(0.00)}{0.13}+\underset{(0.00)}{0.04} E^{2} N_{t}+\underset{(0.00)}{0.10} U I N_{t}^{+}-\underset{(0.07)}{0.06 U I N_{t}^{-}}+\underset{(0.28)}{0.09} R P V I_{t-1}+\varepsilon_{t}
$$

Adjusted $\mathrm{R}^{2}=0.16 ; \quad$ Breusch-Godfrey test $=0.32$.

Equation (13) shows that both expected and positive unexpected inflation are significant while negative unexpected inflation is not. Moreover, the coefficients of positive and negative unexpected inflation are not statistically equal given that the value of the $\chi^{2}(1)$ is 14.61 . Therefore, the above results hold.

In short, for high inflation periods, volatility and all components of inflation are relevant in explaining RPVI, but for moderate regimes determinants of RPVI are quite different. More precisely, volatility and uncertainty are not significant, and the impact of expected and unexpected inflation depends on the inflationary context.

\section{Conclusions}

This paper analyses the relationship between inflation and RPVI in a high and volatile inflationary environment like the Argentinian economy in the period 1960-1993, focusing on the role of inflation regimes in explaining the changes in the determinants of RPVI. We have divided the whole sample into two main periods: the first one (1960-1975) characterized by a moderate and stable inflation, and the second one (1975-1993) characterized by a very changing inflation rate. We identify four inflation regimes: moderate, high, very high, and hyperinflation. We conclude that the determinants of RPVI changes not only with the regime but also with the inflationary context. In particular, the determinants of RPVI in moderate inflation change from the first period of stable inflation to the second period with a changing inflation environment.

For high, very high, and hyperinflation regimes, volatility and all components of inflation (uncertainty, expected and unexpected inflation) are relevant in explaining RPVI but for the moderate regime, determinants of RPVI differ: volatility and uncertainty are not significant, and the impact of expected and unex- 
pected inflation depends on the inflationary context. For the moderate regime in a stable inflation period, expected and positive unexpected inflation are significant while for moderate regime in a changing inflation period, expected inflation is not significant and the magnitude, and not the sign, of unexpected inflation is significant. Moreover, results are not sensitive to the forecast equation of inflation. These results show that, in all regimes, there is a welfare cost of inflation through its impact on RPVI, but there is not a unique theoretical model to explain how and why inflation affects RPVI. In fact, we have found evidence that favors the menu cost model (moderate regime in stable inflation period) and the extended signal extraction model (moderate regime in changing inflation period).

These results are similar to those found by several authors for countries with a much lower inflation than the moderate inflation rate in Argentina -see Table 1-. The intuition behind our results is that the determinants of RPVI depend on the inflationary experience of the economy and not on the absolute value of the rate of inflation. In other words, the lowest inflation period in Argentina has not been even reached by U.S. or Germany in their periods of highest inflation, but theories like menu costs model or signal extraction model can explain the behavior of RPVI in the lowest inflation periods of different economies, because what matters is the relative, and not the absolute, value of the inflation rate. The natural extension of this paper is to analyze the determinants of RPVI in countries with a similar inflationary experience like Argentina.

\section{REFERENCES}

Aarstol, M. (1999), “Inflation, Inflation Uncertainty, and Relative Price Variability”, Southern Economic Journal 66 (2): 414-423.

Altavilla, C. and M. Ciccarelli (2007), "Inflation Forecasts, Monetary Policy and Unemployment Dynamics: Evidence from the U.S. and the Euro Area", Working Paper Series 725, European Central Bank.

Amano, R.A. and R. Macklem (1997), "Menu Costs, Relative Prices, and Inflation: Evidence for Canada", Working Paper 97-14, Bank of Canada.

Barro, R.J. (1976), "Rational Expectations and the Role of Monetary Policy", Journal of Monetary Economics 2 (1): 1-32.

Binette, A. and S. Martel (2005), "Inflation and relative price dispersion in Canada: An empirical assessment", Working Paper 2005-28, Bank of Canada.

Blejer M. (1981), “The Dispersion of Relative Commodity Prices under very Rapid Inflation”, Journal of Development Economics 9 (3): 347-356.

Blejer, M. and L. Leiderman (1982), "Inflation and Relative Price Variability in the Open Economy”, European Economic Review 18 (2): 387-402.

Bollerslev T. and J. Wooldridge (1992), "Quasi-maximum Likelihood Estimation and Inference in Dynamic Models with Time Varying Covariances". Econometric Reviews 11: 143-172.

Caglayan, M. and A. Filiztekin (2003), "Nonlinear Impact of Inflation on Relative Price Variability", Economics Letters 79 (2): 213-218. 
Caraballo, M.A., C. Dabús and D. Caramuta (2006), "A Non-Linear "Inflation-Relative Price Variability" Relationship: Evidence from Latin America", Working Paper E2006/09, Centro de Estudios Andaluces.

Cukierman, A. (1983), "Relative Price Variability and Inflation: A Survey and Further Results", in K. Brunner and A. H. Meltzer (eds.): Variability in Employment, Prices, and Money. Amsterdam, Elsevier Science Publishers.

Dabús, C. (2000), "Inflationary Regimes and Relative Price Variability: Evidence from Argentina", Journal of Development Economics 62 (2): 535-547.

Dazinger, L.(1987), "Inflation, Fixed Cost of Price Adjustment, and the Measurement of Relative Price Variability: Theory and Evidence", American Economic Review 77 (4): 704-713.

Domberger, S. (1987), "Relative Price Variability and Inflation: a Disaggregated Analysis", Journal of Political Economy 95 (3): 547-566.

Fernández, C.(2000), "Inflación e Incertidumbre Inflacionaria: El Caso de Paraguay”. Central Bank of Paraguay, mimeo.

Fielding, D. and P. Mizen (2000), "Relative Price Variability and Inflation in Europe", Economica 67 (265): 57-78.

Fischer, S. (1981), "Relative Shocks, Relative Price Variability, and Inflation”, Brookings Papers on Economic Activity 2: 381-431.

Fischer, S. (1982), "Relative Price Variability and Inflation in the United States and Germany", European Economic Review 18 (1): 171-196.

Grier, K.B. and M.J. Perry (1996), "Inflation, Inflation Uncertainty, and Relative Price Dispersion: Evidence from Bivariate GARCH-M Models", Journal of Monetary Economics 38: 391-405.

Hamilton J. (1989), "A New Approach to the Economic Analysis of Nonstationary Time Series and the Business Cycle", Econometrica 57 (2): 357-384.

Hamilton J. (1994), Time Series Analysis, Princeton University Press, Princeton, New Jersey.

Hercowitz, Z.(1981), "Money and Dispersion of Relative Prices", Journal of Political Economy 89 (2): 328-356.

Lach, S. and D. Tsiddon (1992), "The Behaviour of Prices and Inflation: An Empirical Analysis of Disaggregated Price Data", Journal of Political Economy 100 (2): 349-389.

Lucas, R.E. (1972), "Expectations and the Neutrality of Money". Journal of Economic Theory 4: 103-124.

Lucas, R.E. (1973), "Some International Evidence on Output-Inflation Tradeoffs", American Economic Review 63 (2): 326-344.

Miszler, J. and D. Nautz (2004), "Inflation and Relative Price Variability in a Low Inflation Country: Empirical Evidence from Germany", mimeo, Goethe University, Frankfurt.

Nautz, D. and J. Scharff (2005), "Inflation and Relative Price Variability in a Low Inflation Country: Empirical Evidence for Germany", German Economic Review 6 (4): 507-523.

Nautz, D. and J. Scharff (2006), "Inflation and Relative Price Variability in the euro area: evidence from a panel threshold model", Working Paper N ${ }^{\circ}$ 14/2006, Deutsche Bundesbank.

Palerm, A. (1991), "Market Structure and Price Flexibility", Journal of Development Economics 36 (1): 37-54.

Parks, R.W. (1978), "Inflation and Relative Price Variability", Journal of Political Economy 86 (1): 79-95. 
Parsley, D.C. (1996), "Inflation and Relative Price Variability in the Short and Long Run: New Evidence from the United States", Journal of Money, Credit and Banking 28 (3): 323-342.

Quddus, M., J.S. Butler and J.T. Liu (1988), "Variability of Inflation and the Dispersion of Relative Prices: Evidence from the Chinese Hyperinflation of 1946-1949", Economic Letters 27 (3): 239-249.

Silver, M. and C. Ioannidis (2001), "Intercountry Differences in the Relationship between Relative Price Variability and Average Prices", Journal of Political Economy 109 (2): 355-374.

Solera, A.(2002), "Inflación e Incertidumbre Inflacionaria: Evidencia para Costa Rica", Working Paper DIE-14-2002-DI, Central Bank of Costa Rica.

Tang, D. and P. Wang (1993), "On Relative Price Variability and Hyperinflation”, Economics Letters 42 (2-3): 209-214.

Tommasi, M. (1993), "Inflation and Relative Prices: Evidence from Argentina", in Sheshinski E. and Y. Weiss (eds.), Optimal Pricing, Inflation and Cost of Price Adjustment, MIT Press, Cambridge (Mass.), pp. 487-513.

Van Hoomissen, T. (1988), "Price Dispersion and Inflation: Evidence from Israel”, Journal of Political Economy 96 (6): 1303-1314.

Vining, D.R. and T.C. Elwertowski (1976), "The Relationship between Relative Prices and General Price Level”, American Economic Review 66 (4): 699-708. 


\section{ApPENDix A \\ Additional Test and Estimates}

TABLE 9

ADF TEST FOR INFLATION

\begin{tabular}{lccccc}
\hline Criterion & $\begin{array}{c}\text { Number } \\
\text { of lags }\end{array}$ & Trend & Constant & T-statistics & P-value \\
\hline Schwarz & 4 & Yes & No & -6.25 & 0.00 \\
Akaike & 11 & No & No & -2.48 & 0.00 \\
Hannan Quin & 6 & Yes & No & -4.52 & 0.00 \\
\hline
\end{tabular}

TABLE 10

RPVI AND VOLATILITY

Argentina January 1960-November 1993

\begin{tabular}{lccccccc}
\hline Estimates & $\alpha$ & $\mathrm{RPVI}_{\mathrm{t}-1}$ & $\mathrm{IN}_{\mathrm{t}}^{2}$ & $\mathrm{VOL}_{\mathrm{t}, 3}$ & $\mathrm{VOL}_{\mathrm{t}, 6}$ & $\mathrm{VOL}_{\mathrm{t}, 12}$ & Adj. $\mathrm{R}^{2}$ \\
\hline I & 0.15 & 0.48 & 0.0003 & 0.02 & & & 0.68 \\
& $(0.00)$ & $(0.00)$ & $(0.00)$ & $(0.00)$ & & & \\
II & 0.26 & 0.12 & 0.0004 & & 0.01 & & 0.63 \\
& $(0.00)$ & $(0.03)$ & $(0.00)$ & & $(0.00)$ & & \\
III & 0.24 & 0.20 & 0.5 & & & 0.009 & 0.73 \\
& $(0.00)$ & $(0.00)$ & $(0.00)$ & & & $(0.00)$ & \\
& & & & & & & \\
\hline
\end{tabular}

\section{APPENDIX B \\ The Markov Switching Regression Model}

The following Markov-switching model with an $A R(1)$ component was fitted to our data:

$$
I N_{t}-\mu\left(s_{t}^{*}\right)=\theta\left(I N_{t-1}-\mu\left(s_{t-1}^{*}\right)\right)+\varepsilon_{t} \text { where } \varepsilon_{t} \approx i . i . d N\left(0, \sigma^{2}\right)
$$

where $s^{*}{ }_{t}$ is described by a three-state Markov chain and the conditional mean $\mu\left(s_{t}{ }_{t}\right)$ switches among the three states (moderate $(m)$, high $(h)$ and very high $(v h)$ inflation regimes). In order to estimate de model, we define the variable $s t$ that characterizes the regime for date $t$ as follows: 
$s_{t}=1$ if $s_{t}^{*}=m$ and $s_{t-1}^{*}=m \quad s_{t}=4$ if $s_{t}^{*}=m$ and $s_{t-1}^{*}=h \quad s_{t}=7$ if $s_{t}^{*}=m$ and $s_{t-1}^{*}=v h$

$s_{t}=2$ if $s_{t}^{*}=h$ and $s_{t-1}^{*}=m \quad s_{t}=5$ if $s_{t}^{*}=h$ and $s_{t-1}^{*}=h \quad s_{t}=8$ if $s_{t}^{*}=h$ and $s_{t-1}^{*}=v h$

$s_{t}=3$ if $s_{t}^{*}=v h$ and $s_{t-1}^{*}=m \quad s_{t}=6$ if $s_{t}^{*}=v h$ and $s_{t-1}^{*}=h \quad s_{t}=8$ if $s_{t}^{*}=v h$ and $s_{t-1}^{*}=v h$

And we denote $p^{*}{ }_{i j}$ as:

$$
p_{i j}^{*}=\operatorname{Pr}\left(s_{t}^{*}=j \mid s_{t-1}^{*}=i\right)
$$

And then st follows a nine-state Markov chain with a transition matrix $P$ :

$$
P=\left|\begin{array}{ccccccccc}
p_{m, m}^{*} & 0 & 0 & p_{m, m}^{*} & 0 & 0 & p_{m, m}^{*} & 0 & 0 \\
p_{m, h}^{*} & 0 & 0 & p_{m, h}^{*} & 0 & 0 & p_{m, h}^{*} & 0 & 0 \\
p_{m, v h}^{*} & 0 & 0 & p_{m, v h}^{*} & 0 & 0 & p_{m, v h}^{*} & 0 & 0 \\
0 & p_{h, m}^{*} & 0 & 0 & p_{h, m}^{*} & 0 & 0 & p_{h, m}^{*} & 0 \\
0 & p_{h, h}^{*} & 0 & 0 & p_{h, h}^{*} & 0 & 0 & p_{h, h}^{*} & 0 \\
0 & p_{h, v h}^{*} & 0 & 0 & p_{h, v h}^{*} & 0 & 0 & p_{h, v h}^{*} & 0 \\
0 & 0 & p_{v h, m}^{*} & 0 & 0 & p_{v h, m}^{*} & 0 & 0 & p_{v h, m}^{*} \\
0 & 0 & p_{v h, h}^{*} & 0 & 0 & p_{v h, h}^{*} & 0 & 0 & p_{v h, h}^{*} \\
0 & 0 & p_{v h, v h}^{*} & 0 & 0 & p_{v h, v h}^{*} & 0 & 0 & p_{v h . v h}^{*}
\end{array}\right|
$$

The conditional density of INt is given by

$$
f\left(I N_{t} \mid I N_{t-1}, s_{t}=N ; \alpha\right)
$$

where $N$ is the number of states $s t=9$ and therefore, there are nine different densities:

$$
\begin{aligned}
& f\left(I N_{t} \mid I N_{t-1}, s_{t}=1 ; \alpha\right)=\frac{1}{\sqrt{2 \pi} \sigma} \exp \left\{\frac{-\left[\left(I N_{t}-\mu_{m}\right)-\theta\left(I N_{t-1}-\mu_{m}\right)\right]^{2}}{2 \sigma^{2}}\right\} \\
& f\left(I N_{t} \mid I N_{t-1}, s_{t}=2 ; \alpha\right)=\frac{1}{\sqrt{2 \pi} \sigma} \exp \left\{\frac{-\left[\left(I N_{t}-\mu_{h}\right)-\theta\left(I N_{t-1}-\mu_{m}\right)\right]^{2}}{2 \sigma^{2}}\right\} \\
& f\left(I N_{t} \mid I N_{t-1}, s_{t}=3 ; \alpha\right)=\frac{1}{\sqrt{2 \pi} \sigma} \exp \left\{\frac{-\left[\left(I N_{t}-\mu_{v h}\right)-\theta\left(I N_{t-1}-\mu_{m}\right)\right]^{2}}{2 \sigma^{2}}\right\}
\end{aligned}
$$




$$
\begin{aligned}
& f\left(I N_{t} \mid I N_{t-1}, s_{t}=4 ; \alpha\right)=\frac{1}{\sqrt{2 \pi} \sigma} \exp \left\{\frac{-\left[\left(I N_{t}-\mu_{m}\right)-\theta\left(I N_{t-1}-\mu_{h}\right)\right]^{2}}{2 \sigma^{2}}\right\} \\
& f\left(I N_{t} \mid I N_{t-1}, s_{t}=5 ; \alpha\right)=\frac{1}{\sqrt{2 \pi} \sigma} \exp \left\{\frac{-\left[\left(I N_{t}-\mu_{h}\right)-\theta\left(I N_{t-1}-\mu_{h}\right)\right]^{2}}{2 \sigma^{2}}\right\} \\
& f\left(I N_{t} \mid I N_{t-1}, s_{t}=6 ; \alpha\right)=\frac{1}{\sqrt{2 \pi} \sigma} \exp \left\{\frac{-\left[\left(I N_{t}-\mu_{v h}\right)-\theta\left(I N_{t-1}-\mu_{h}\right)\right]^{2}}{2 \sigma^{2}}\right\} \\
& f\left(I N_{t} \mid I N_{t-1}, s_{t}=7 ; \alpha\right)=\frac{1}{\sqrt{2 \pi} \sigma} \exp \left\{\frac{-\left[\left(I N_{t}-\mu_{m}\right)-\theta\left(I N_{t-1}-\mu_{v h}\right)\right]^{2}}{2 \sigma^{2}}\right\} \\
& f\left(I N_{t} \mid I N_{t-1}, s_{t}=9 ; \alpha\right)=\frac{1}{\sqrt{2 \pi} \sigma} \exp \left\{\frac{-\left[\left(I N_{t}-\mu_{v h}\right)-\theta\left(I N_{t-1}-\mu_{v h}\right)\right]^{2}}{2 \sigma^{2}}\right\} \\
& f\left(I N_{t} \mid I N_{t-1}, s_{t}=8 ; \alpha\right)=\frac{1}{\sqrt{2 \pi} \sigma} \exp \left\{\frac{-\left[\left(I N_{t}-\mu_{h}\right)-\theta\left(I N_{t-1}-\mu_{v h}\right)\right]^{2}}{2 \sigma^{2}}\right\}
\end{aligned}
$$

And $\alpha$ is a vector of parameters characterising the conditional density:

$$
\alpha=\left(\mu_{m}, \mu_{h}, \mu_{v h}, \theta, \sigma^{2}\right)^{\prime}
$$

Moreover, it is assumed that st evolves according to a Markov chain that is independent of past observations on $I N_{t}$. $\operatorname{are}^{11}$ :

Finally, the maximum likelihood estimates of parameters in $\alpha$ for our data

$$
\alpha=(4.44 \%, 19.12 \%, 41.99 \%, 0.82,10.13)
$$

\footnotetext{
${ }^{11}$ As it was stated above, hyperinflation period was excluded. The arithmetic mean inflation rate for such period was $97.5 \%$.
} 